\title{
Research on the Teaching Reform of Probability Theory and Mathematical Statistics Based on Professional Application
}

\author{
CHONG Xiaowen \\ College of Mathematics and Statistics, Baicheng Normal University, Baicheng,137000,China \\ email: chongxiaowen@163.com
}

Keywords: Professional Application, Probability Theory, Mathematical Statistics, Teaching Reform

\begin{abstract}
When teaching reform in the discipline of probability and mathematical statistics, teachers should fully combine the characteristics of the subject. Teachers need to take professional applications as the guidance of reform, explore the main problems existing in the current teaching situation, actively transform the concept of teaching, and fully understand the importance of practical application for discipline development. Teachers need to optimize the content of teaching, strengthen the practice and application of teaching, and innovate the teaching model and evaluation system. This article will analyze the teaching reform of the discipline of probability and mathematical statistics under the guidance of professional application, and put forward the corresponding ways and methods of reform.
\end{abstract}

\section{Introduction}

Probability theory and mathematical statistics, belong to mathematics category, mainly studies the regularity of random phenomena in statistics. It is widely used in many fields of securities investment, economic forecasting and management and insurance. With the deepening of our educational system reform and the continuous development of the economic situation, schools need to cultivate practical talents with practical ability as the goal of training. The cultivation of applied talents needs to further improve the quality of teaching, and truly implement the concept and goal of teaching reform, which is also the key link of the subject education. Therefore, in-depth analysis of the characteristics of the subject teaching teachers should correctly handle the relationship between teaching and learning of professional knowledge, to cultivate students' ability in practical application and innovation consciousness through the process of teaching, which is the core of the reform of teaching contents of courses [1].

\section{The Main Problems and Reasons in the Current Course Teaching of Probability and Statistics}

The Main Problems. The Task of Teaching is Relatively Heavy, but the Set Hours are Relatively Small. The teaching content of probability and statistics cover the distribution of random variables and random variables, the digital characteristics of the sample and the sampling distribution, variance and regression analysis, adding test, parameter estimation and large numbers and the central limit theorem. The teaching task is very heavy, but the corresponding teaching hours is less, cause to further analyze the practice teaching time and reduce teachers in order to pursue the completion of teaching tasks, lack of training students to use the knowledge.

The Content of Teaching is Abstract and Difficult to Understand, which Affects the Students' enthusiasm for Learning. The teaching content of the subject involves many abstract concepts, methods and application of the system is very complex, resulting in many students find it difficult to understand the specific relationship between curriculum and professional learning set between. This will affect the students' interest in learning, and the learning difficulties exist in quite a number of students. The students in the daily study of the subject of investment is relatively small, the efficiency and results of learning are relatively poor, they can not play should play the basic curriculum as a professional learning of the subject [2]. 
The Mode of Teaching is Relatively Simple, and the Teaching of Practical Application is Ignored. Many teachers use the traditional teaching mode in the teaching, the teaching content confined to textbooks, and simply rely on the mechanical teaching method. At the same time the evaluation mechanism of knowledge is still in a test phase, which makes it difficult for students to get hands-on opportunities, it is difficult to form a deep theoretical knowledge understand, cause students can not use knowledge to solve practical professional problems.

The Main Cause of the Problem. With the rapid development of China's economy and society, and the probability and statistics related disciplines such as economics and management professional has taken place in the personnel training goal of major changes, but as the probability and statistics of basic science in the teaching concept, mode and content and method has not changed in time [3].

After the change of training objectives and programs, if we continue to carry out relevant teaching according to the traditional training objectives of academic talents, we will inevitably lead to contradictions between teaching and learning.

After changing in the course of efficacy, training applied personnel training must be in accordance with the actual needs of the community. The probability and statistics subject as the basic subject is a part of the application of professional talents, its main role is to cultivate students' mathematical thinking, analysis and solving ability so that students can master the use of mathematical methods the major practical problems. Focus on skills training and operation ability of numerical calculation teaching mode can not adapt to the actual needs of professional use.

The teaching mode is changed, training applied talents more emphasis on theoretical knowledge and practice, the traditional pursuit of profound whole teaching ideas and ways to test and problem centered teaching, lack of serious and practical application closely, but also lack of practice and corresponding case teaching, affecting students' learning results [4].

\section{The Main Ideas of Teaching Reform in the Course of Probability and Statistics}

The professional application oriented teaching reform requires the school to clearly apply the training goal of the talents, conforms to the syllabus and the ability to develop the application.

Clear the Goal of Reform. The goal of teaching reform is to set up a teaching and training system that can meet the needs of our economic and social development, and improve the quality of teaching in an all-round way, and lay a good foundation for the cultivation of applied talents [5].

Realize the Transformation of Function Positioning and Evaluation System. The school needs to be repositioned on the probability and statistics teaching function, make the transition from the subject to complete system application needs attention practical. And the corresponding evaluation system also take the traditional focus on examination results to practical application ability to change.

The Reform must be Closely Integrated with the Characteristics of the Subject and the Actual Situation. Teaching reform should adhere to the teaching contents should be closely combined with professional knowledge, professional knowledge and mathematical to form mutual penetration. Teachers should with probability and statistics teachers closely together to participate in the teaching reform, which has been applied to establish teacher team. In the teaching process, teaching theory adhere to the organic integration and case teaching, creating open teaching system.

Pay Attention to the Ability to Cultivate Students. Probability and statistics need to cultivate students' mathematical thinking ability in teaching practice; cultivate students' autonomous learning ability in the interactive teaching; to cultivate students' ability of innovation through mathematical modeling activities; the use of cooperative learning methods, cultivate students' ability to cooperate [6]. 


\section{The Reform Approach of the Probability and Statistics Under the Guidance of Professional Application}

Improving the Comprehensive Quality of Teachers and Actively Changing the Concept of Teaching. The improvement of teachers' quality and the change of teaching ideas are the key and foundation for promoting the reform of subject teaching. Teachers should carry out the guidance of professional application in teaching, and establish the teaching ideas of analyzing and solving practical problems by mathematical theory. Probability and statistics, and should strengthen the professional application of other professional management such as communication and exchanges, expand their professional qualities, to learn more professional knowledge, but also with other application of professional teachers develop teaching syllabus, improve writing teaching content, in order to make courseware, and the design of more relevant cases suitable for practice teaching. Teachers promote the related teaching research through teaching activities and improve the quality of teachers in the course of teaching and research [7].

Optimizing the Content of Teaching and Widening the Students' knowledge System. To reform the teaching content of courses is a key point in teaching reform. By optimizing the teaching content, and the application of probability and statistics of professional theoretical knowledge and professional knowledge to the students' organic integration can effectively broaden the students' knowledge, and develop the students' thinking, not only embodies the relation between subject and teaching other economic management professional, also can according to the actual needs of the application of professional knowledge, to optimize the teaching syllabus, teaching content to develop more professional training objectives.

Playing the Main Role in the Teaching Activities of the Students. Teachers should fully recognize the main role of students in teaching activities, to reform the traditional students in the status and role of passive receiving, let the students in inquiry learning. Teachers should actively advance the preview task to assign the students, to enable students to preview the content of the course in the course of teaching., teachers should focus on the difficulties of the content and related examples and related application case. Then, teachers should encourage students to ask teachers to answer questions, and can organize students to debate on. Teachers should create a lively democratic learning atmosphere in the classroom for students, and encourage students question. Teachers should establish an equal relationship with the students, the students approached, and the subject content to guide students to establish a correct outlook on life and values. In the teaching, teachers can We should guide students to focus on the future and direction of discipline application, and guide students to master important practical application methods. For basic theoretical knowledge, teaching should focus on students' understanding of their basic thinking methods.

Innovating the Mode of Teaching. The teaching reform of the subject is mainly about teaching mode of the reform, so as to cultivate students' interest in learning, and gradually cultivate the students' ability of autonomous learning. Teachers should pay attention to the calculation and analysis of knowledge and practical combination of theory and case analysis in teaching, theoretical knowledge of probability statistics is explained through the case. This can make relatively obscure and abstract theoretical terms easy to understand. We need to introduce the practical application of numerical calculation in the case, so as to solve practical problems, to achieve the theoretical knowledge and professional use of the organic combination of purpose. Teachers can also through the reasonable design of the situation in the classroom teaching, guide students to learn and study the problem in packet mode, and in the classroom discussion, classroom learning atmosphere, cultivating students' autonomous learning habit and ability.

Actively Applying the Modern Network Information Technology to Enrich the Means and Methods of Teaching. Teaching should actively use modern network information technology in the teaching, change the limitations of practice and space for teaching activities. Some of the more suitable teaching content unified explanation, teachers can through the network video. As long as the basic video terminal hardware conditions, a teacher to students of different majors in the different space teaching. Of course teachers should also not ignore the students and face-to-face 
exchanges and communication. In the network are able to store large amounts of teaching information, and can realize the sharing and form of multimedia content can form a strong stimulus to students, which can effectively improve the efficiency of teaching. In addition, for some practical teaching the content, teachers can organize the students into the practical application environment of enterprise.

Strengthening the Practical Application Teaching in the Teaching and Improving the Students' ability in Practical Application. The teaching reform of professional application oriented, practice teaching reform is the key to the students to use. In response to professional practice in students knowledge. Teachers can guide the students to carry out exploratory testing, and through the interpretation of the test results to help students deepen the understanding of theoretical knowledge, cultivate students gradually formed ability to find and solve practical problems. Teachers can also encourage students to carry out academic innovation activities, and to provide support and guidance for the academic and academic organization in some mathematical modeling contests and other activities, based on the mathematical knowledge of the practice of cultivating students' innovative consciousness and ability.

Innovating the Evaluation System and Mobilizing the Enthusiasm of Students' learning. Teaching evaluation methods should adapt to the teaching reform, and to reform the results to the test. The effect on students' school assessment depends entirely on the final exam. To achieve the application of the guidance of professional personnel training objectives to the students the ability to use knowledge to focus on the assessment, so we should innovate the evaluation system, students can be in class discussion and practice in the performance are incorporated into the examination, and final exam grades and attendance daily consisting of the evaluation results, the evaluation mechanism of examination oriented education to change the one-sided pursuit of test scores, so as to promote the students to change their learning styles, pay more attention to the process of daily learning, mobilize students' enthusiasm for learning, to improve the students' comprehensive quality and practice ability of the teaching goal.

\section{Conclusion}

The subject of probability and mathematical statistics should be carried out in depth under the guidance of professional application. It is necessary to change the current situation that the professional theory can not be combined with the practical application. Therefore, teachers in the teaching of probability and statistics in strengthening the combination of theory and practice of planning and implementation, to fully tap the professional theory, discipline thinking method. The actual formation is closely associated with the modernization of production and life can be in a related case or model, or the ability to analyze and solve practical problems. Part of the teachers can be thought and test methods of modeling into organic teaching methods or approaches, the case teaching to be enriched, it can effectively improve students' flexible use of theoretical knowledge to solve practical problems are analyzed and the ability and consciousness. So as to realize the cultivation of students' practical ability and innovative spirit of the teaching objectives, training more in the new era with high comprehensive quality of talents for the society.

\section{References}

[1]YANG Shufen. Research on the teaching reform of probability and mathematical statistics based on professional application[A] .The new education era[C].:,2015:2.

[2]SU Jing,XIAO Pan. Research on the teaching reform of probability and mathematical statistics based on professional application[J]. Guangxi Journal of Light Industry,2014,(19):140+146.

[3]YIN Heyi. Research on the teaching reform of probability and mathematical statistics based on professional application[J]. Consume Guide, 2016(12).

[4]GUO Changhe, PANG Yanjun. Research on application oriented teaching reform of "probability 
theory and mathematical statistics"[J]. Journal of Hebei University of Engineering(Social Science Edition), 2014, 31(2):98-100.

[5]DING Guiyan, LIU Hao, HE Xiqin. Thinking on the research of the teaching reform of probability and mathematical statistics[J]. Contemporary Education Research and Teaching Practice, 2017(5).

[6]YIN Liangliang, ZHANG Wenliang, WU Meng. Reflection on the reform of probability theory and mathematical statistics practice teaching[J]. Exploration of Financial Theory, 2014(3):72-74.

[7]YIN Shuo, CONG Yuhua, YU Meiju. Exploration and practice of the teaching of probability and mathematical statistics[J]. Journal of Tonghua Normal Uninversity, 2016, 37(12):105-107. 